This item was submitted to Loughborough's Research Repository by the author.

Items in Figshare are protected by copyright, with all rights reserved, unless otherwise indicated.

\title{
Emotions and the habitus: young people with socio-emotional differences (re)producing social, emotional and cultural capital in family and leisure space-times
}

\section{PLEASE CITE THE PUBLISHED VERSION}

http://dx.doi.org/10.1016/j.emospa.2013.02.002

\section{PUBLISHER}

(C) Elsevier Ltd.

\section{VERSION}

AM (Accepted Manuscript)

\section{LICENCE}

CC BY-NC-ND 4.0

\section{REPOSITORY RECORD}

Holt, Louise, Sophie Bowlby, and Jennifer Lea. 2019. "Emotions and the Habitus: Young People with Socioemotional Differences (re)producing Social, Emotional and Cultural Capital in Family and Leisure Spacetimes". figshare. https://hdl.handle.net/2134/13086. 
This item was submitted to Loughborough's Institutional Repository (https://dspace.lboro.ac.uk/) by the author and is made available under the following Creative Commons Licence conditions.

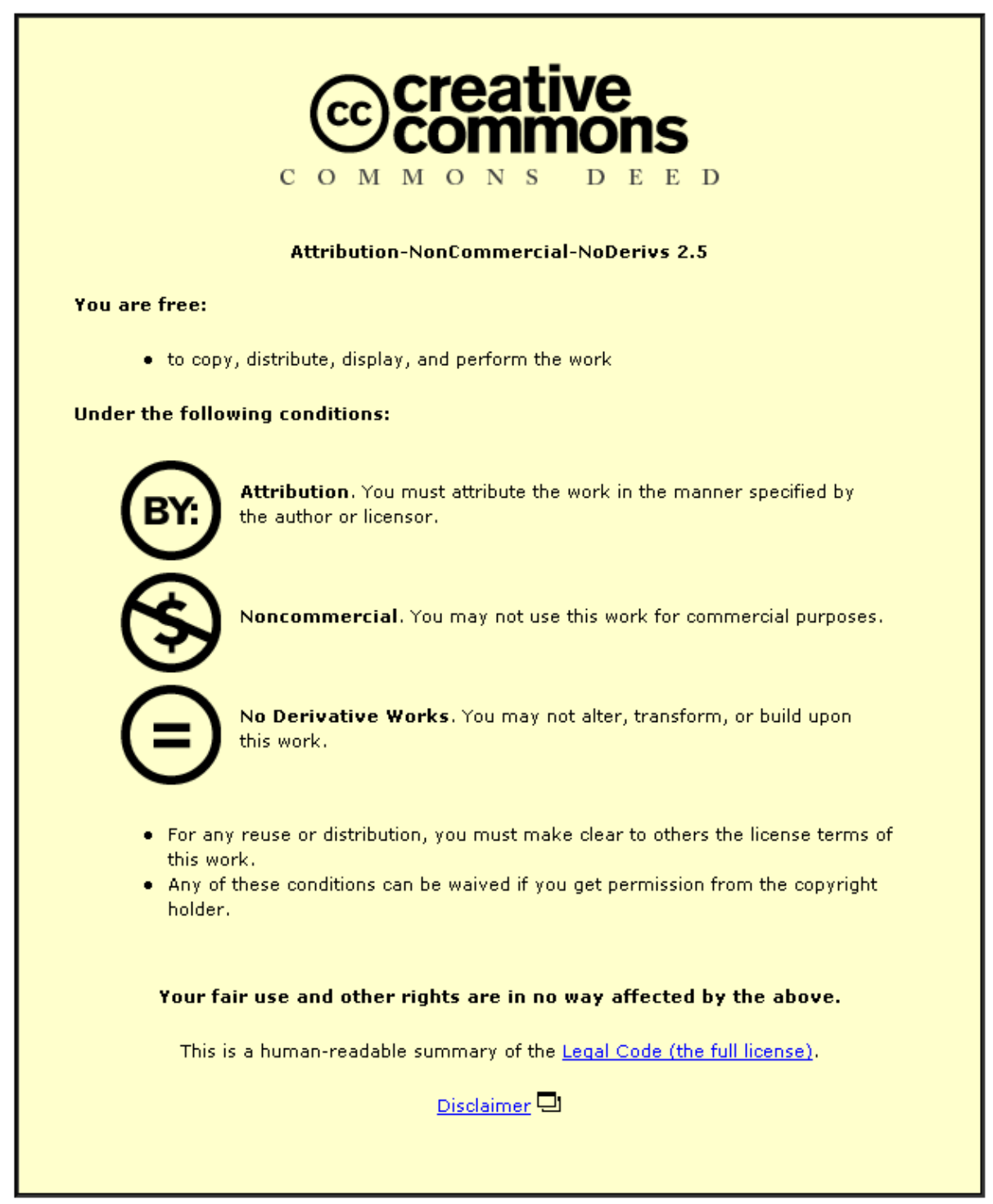

For the full text of this licence, please go to: http://creativecommons.org/licenses/by-nc-nd/2.5/ 
Emotions and the habitus: young people with socio-emotional differences (re)producing social, emotional and cultural capital in family and leisure space-times

\section{Abstract}

In this paper we explore the importance of emotionally inter-dependent relationships to the functioning of embodied social capital and habitus. Drawing upon the experiences of young people with socio-emotional differences, we demonstrate how emotionally interdependent and relatively nurturing relationships are integral to the acquisition of social capital and to the co-construction and embodiment of habitus. The young people presented in this paper often had difficulties in forging social relationships and in acquiring symbolic and cultural capital in school spaces. However, we outline how these young people (re)produce and embody alternative kinds of habitus, based on emotionally reciprocal relationships forged through formal and informal leisure activities and familial and fraternal social relationships. These alternative forms of habitus provide sites of subjection, scope for acquiring social and cultural capital and a positive sense of identity in the face of problematic relations and experiences in school spaces.

\section{Key words}

Habitus, emotional capital, social capital, young people, socio-emotional differences, Social Emotional and Behavioural Difficulties (SEBD) 
Emotions and the habitus: young people with socio-emotional differences

(re)producing social, emotional and cultural capital in family and leisure space-times

\section{Introduction}

This paper focuses upon the embodied social capital of young people with socioemotional differences ${ }^{i}$ whose identities are devalued within school spaces. All of the young people in the paper were diagnosed, via the Special Educational Needs (SEN) institution, as having Social, Emotional and Behavioural Difficulties (SEBD). This label is applied to young people whose behaviour is 'out of place' with their school context, and viewed as a barrier to their own learning and/or to that of their peers (Youdell and Armstrong, 2011). We use the term socio-emotional differences to emphasise that the 'difficulties' the young people face are socio-spatially constituted in relation to shifting 'norms' of appropriate behaviour and embodied and experienced differences (Holt, 2010). These two facets are intrinsically interconnected and difficult to unravel in the experience of young people. All of these young people had a problematic relationship to formal education, and were often viewed negatively by many teachers and other adults in the school. In addition, the majority of the young people discussed in this paper had problematic social relationships with peers within school; and reported having few or no friends, or exceptionally unstable, diffuse, conflictual and shifting peer relationships.

In this paper we explore how the emotional and affective geographies of young people's social relationships with friends and family in familial and formal and informal leisure spaces provide positive counter-habituses to their negative experiences in schools, generating a sense of themselves as skilled and proficient, or as capable of constructing and maintaining friendships. These counter-habituses 
Emotions and the habitus: young people with socio-emotional differences (re)producing social, emotional and cultural capital in family and leisure space-times

can be embodied and taken into encounters in other spaces, including those of the school. Here we emphasise the importance of emotions and affect to the (re)production of social capital and habitus. We argue that social relationships are largely forged and maintained specifically because individuals are emotionally codependent and seek satisfying and supportive relationships and networks. Thus, contrary to dominant views of social capital, which (re)produce a narrow, strategic and rational view of agency, we suggest that social 'capital' is, at heart, largely based upon emotional and affectual relationships that exceed rational agency. As Holt has (2008) argued, capital and habitus emerge through beyond-conscious acts rather than strategic, rational agency. However, here this argument is taken further to emphasise the importance of emotions and affect within these beyond-conscious acts, drawing upon Butler's $(1997 ; 2004)$ notions of subjection and recognition, which place social and emotional inter-dependency at the heart of explaining how individuals implicate themselves in subjection. Thus, whereas Reay (2004a) identified the importance of the emotional as a key form of capital that has been largely overlooked, we take this further to suggest that emotions are at the heart of the operation of social and cultural capital and the embodiment of habitus. The paper is broadly situated within endeavours to take the emotions more fully into account within education research (Kenway and Youdell, 2011) and attempts to expand norms of behaviour by exploring the experiences of those whose practices fall outside of socio-spatially shifting expectations (Davidson, 2010; Davidson and Parr, 2010; Sakellariadis, 2012). 
Emotions and the habitus: young people with socio-emotional differences (re)producing social, emotional and cultural capital in family and leisure space-times

The paper proceeds through six sections. In the following section, the conceptual and theoretical stance is outlined. Section 3 outlines the methods by which the data drawn upon in the paper were collected. Sections 4 and 5 present the empirical data, examining how young people forge social, cultural and emotional capital outside school spaces (Section 4) before developing our analysis of emotional capital, subjection and the embodiment of habitus (Section 5). The final section offers a conclusion.

\section{Embodied social capital, habitus and emotional capital}

Embodied social capital synthesises insights from Bourdieu's theories of capitals and habitus (1986, 1990; Reay, 2004b) and Butler's performativity and subjection (1990, $1993,1997,2004)$ to express how everyday performances (re)produce variously (de)valued embodied identities that locate individuals materially; (re)producing or transforming broader societal inequalities (Holt, 2008, 2010). Crucially, the ways in which identities are performed are not fixed; they are contextual, influenced by individuals' social networks, and spatially embedded. These variously valued identities can become inculcated and embodied as 'habitus', providing a context for future socio-spatial encounters.

Habitus is a complex concept, which defies straightforward definition (Lizardo, 2004). It has been applied differently across geography and within sociologies of education 
Emotions and the habitus: young people with socio-emotional differences (re)producing social, emotional and cultural capital in family and leisure space-times

(Bridge, 2006; Holt, 2008; Reay, 2004a; Waters, 2006). One (of many) definitions is proffered by Bourdieu (1998: 25):

"The habitus is this kind of practical sense of what is to be done in a given situation - what is called in sport a "feel" for the game, that is, the art of anticipating the future of the game, which is inscribed in the present state of play" (Emphasis in original).

As habitus is such a slippery concept, it is important to highlight how we use it here. We understand habitus to become via an interaction between individual and collective bodies and socio-spatial contexts or 'fields' or external social realities (Butler, 1998). Habitus is a set of embodied dispositions - tastes, preferences, ways of being, accents, and so on, which form an unconscious backdrop to (future) social encounters (Bourdieu and Thompson, 1991; Reay, 2004a). As bodies can be conceived as porous and unbounded, connected to other bodies and only becoming in specific spatial contexts and in relation to a variety of human and non-human actors (Colls, 2011), habitus can be understood as simultaneously a property of individuals and collectives, and has even been tied to particular spaces (Smith and Phillips, 2001). Thus, habitus mostly operates at sub- or beyond-conscious levels; transformation of habitus largely occurs via beyond-conscious responses to new 'fields' rather than deliberate attempts at change (Bourdieu and Thompson, 1992). Ultimately, the concept of habitus, in line with much of Bourdieu's work, attempts to unravel how individuals and collectives reproduce enduring socio-economic differentials via 
Emotions and the habitus: young people with socio-emotional differences (re)producing social, emotional and cultural capital in family and leisure space-times

everyday practices (Bourdieu, 1984, 1986, 1990; Bourdieu and Passeron, 1979). For instance, since the privileged have more access to cultural and social capital, they are better able to predict the future of the game, such as the relative future prestige to be accorded to different universities and courses (Bourdieu and Passeron, 1979). Hence habitus "is one of the mediations through which scholastic - and social - success are linked to social origin" (ibid. p. 72).

In short, young people's social networks and relationships influence the capitals to which they have access: cultural, symbolic, social and economic. Of particular interest to us is how the values and mores of young people's social networks reproduce particular forms of habitus, which can become embodied into their individual identities and senses of themselves. These forms of habitus then provides a backdrop to future encounters in other settings, influencing young people's social relationships and access to capitals.

Bourdieu's theories of how everyday, embodied, affective practices act as a mechanism for the (re)production of (classed) identities have had a significant impact on the broader social sciences (Atkinson, 2009; Reay, 1998; Skeggs, 1997). Although this has filtered into geography (e.g. Cresswell, 2004; Dowling, 2009; Jeffrey, 2010; Hollingworth, Williams, Jamieson and Beedell, 2011; Holt, 2010; McDowell, 2003, 2006; Willis, 2008; Reay, 2007), geographers' engagement with Bourdieu has not reflected the vast and enduring dialogue present within other disciplinary fields. This is unfortunate, since Bourdieu offers important insights to 
Emotions and the habitus: young people with socio-emotional differences (re)producing social, emotional and cultural capital in family and leisure space-times

endeavours to enhance the materiality of geography, particularly the need to reengage with historical-materialism, class and enduring material inequalities (Dowling, 2009; Jackson, 2000; Philo, 2000; although see Anderson and Wylie, 2009 for a critique) along with corporeal bodies (Colls, 2011; Longhurst, 1997; McNay, 2004).

In an important intervention, Reay (2004a) emphasises that Bourdieu neglects emotional aspects of social relationships, particularly the nurturing emotional 'work' of women (especially mothers) in families. Reay (ibid.) questions the extent to which mothers' emotional investment in their children translates into a resource that can be drawn upon as 'emotional capital', developing a term coined by Nowotny (1981). Importantly, Reay (ibid.) does not equate all emotional investment to capital. She regards those mothers who are able to regulate their own emotions, had a positive experience of school, and can avoid reproducing the excesses of middle-class pressures for educational success, as able to generate the most effective emotional capital.

Although applauding Reay's significant and highly influential enhancement of Bourdieu, we would like to make four sympathetic criticisms, which this paper then begins to address. First, despite her best efforts, in suggesting that emotional relationships provide more or less 'capital', a value judgement is made, in which largely (with a few exceptions) middle-class mothers who can temper the pressure to succeed educationally, provide the most emotional capital. Second, and relatedly, the value of emotional capital is therefore implicitly tied to its potential to be 
Emotions and the habitus: young people with socio-emotional differences (re)producing social, emotional and cultural capital in family and leisure space-times

converted into other, cultural, and ultimately economic, forms of capital, reproducing a view of Bourdieu as being, at heart, a materialist. Whereas one of the key contributions of Bourdieu is his attention to economic inequalities and values, to equate all value or aspects of life to the economic is problematic. In this paper, we assume that all emotional relationships are valued by those involved, even when they have problematic aspects as most do to a greater or less extent. Third, given the focus of Reay's (ibid.) study, mothers are positioned as the key providers of emotional capital. Here we focus on the emotional capital provided by friends and all family members - mothers, fathers, grandparents, siblings, step-parents. This engages with recent developments in geography that have begun address the previous relative neglect of the entangled emotional geographies of families and friendships within the lives of children and young people (e.g. Blazek, 2011; Dyson, 2010; Harker, 2010; Lewis, 2011; Valentine, 2008; Valentine and Hughes, 2011a). Fourth, and perhaps most importantly, by positing the emotional as another form of capital, Reay underplays significance of the emotions. Drawing upon Butler (2004), we suggest that, rather than simply another form of capital, emotional relationships underpin the acquisition of social and cultural capital, and the development of habitus.

Bourdieu's theories of capitals, habitus and fields arguably do not fully address how and why individuals and collectives accept their location within particular fields and embody capitals as habitus. By contrast, Judith Butler's concepts of subjection and recognition, and her exploration of the psychic operations of power, give a greater 
Emotions and the habitus: young people with socio-emotional differences (re)producing social, emotional and cultural capital in family and leisure space-times

sense of how habitus becomes inculcated into individual and collective bodies (Butler, 1997,1998, 2004; Holt, 2008), although her conceptualisations of agency and how it is structured are not above criticism (McNay, 2004; Holt, 2007). Despite Butler's sustained influence within geography, particularly on feminist and nonrepresentational strands of the discipline, her works on subjection and the psychic life of power have been relatively under-explored (Thomas, 2010, although see Bondi, 2005; Gallagher, 2011; M. Rose, 2002; Werner, 2006). In her 1997 and 2004 works, Butler synthesises Foucault with post-Freudian psychoanalytical theory to critique the notion of an interior psyche and to explore how the emotional (and to a lesser extent physical) (inter-)dependency of humans predisposes the acceptance and psychic incorporation of regulatory norms (which are not static, but can be transformed). Importantly, then, emotional inter-dependency and an (almost) universal need for humans to be emotionally recognised and socially valued underpin why individuals locate themselves in subjection and, therefore, we argue, by extension how individuals embody particular conditions of social, cultural and economic capital as habitus. As Butler (2004: 22) states, focusing on grief, it "contains within it the possibility of apprehending the fundamental sociality of embodied life, the ways in which we are from the start, and by virtue of being a bodily being, we are already given over, beyond ourselves, implicated in lives that are not our own".

Here we synthesise Butler and Bourdieu. We recognise this as a slightly problematic endeavour due to their differing philosophical staring points, with Butler emphasising 
Emotions and the habitus: young people with socio-emotional differences (re)producing social, emotional and cultural capital in family and leisure space-times

discourse and language and Bourdieu more closely aligned to (historical) materialism (McNay, 2004; Grenfell, 2004). Despite this, Butler (1999) has engaged in generative dialogue with Bourdieu's habitus. Furthermore, their projects have many overlaps, such as deconstructing body/society and structure/agency dualisms. Using both authors together can help to overcome some of the limitations emerging from their differing philosophical and theoretical groundings. Butler's theories of subjection and recognition help to explain the 'black box' of the beyond-conscious ways in which capitals become inculcated in individual and collective bodies as habitus. Her positioning of emotional inter-dependency and the need for recognition as integral for explaining how and why people become subjected in power provides a launch-pad to examine how emotionally reciprocal (although always conflictual, unequal, problematic) relationships are important to the development of habitus and the inculcation of capitals. Embodied in individuals and collectives, habitus then provides a context for future social encounters and/or a set of dispositions which promote or constrain the acquisition of other capitals.

In this paper, we explore these issues in relation to young people with socioemotional differences, who mostly had problematic social relationships at school and difficulties in acquiring symbolic and cultural capital in the school education field. We consider how the emotionally reciprocal relationships that these young people had with families and friends in non-school spaces provided an alternative form of social capital, which became embodied as habitus, establishing an alternative context for social encounters in other spaces, including within school spaces. Even families and 
Emotions and the habitus: young people with socio-emotional differences (re)producing social, emotional and cultural capital in family and leisure space-times

friends considered problematic by many key actors provided social and emotional capital.

\section{Methods}

The empirical material in this paper is drawn from research with 13 young people with socio-emotional differences who attended two different secondary schools in two different Local Authoritiesii (LAs). All the young people whose experiences are presented here had a diagnosis of Social Emotional and Behavioural Differences (SEBD). Two were also were considered to have specific learning 'difficulties' and one was also labelled as on the Autistic Spectrum (AS). Although the focus of the paper is the reflective experiences of young people, semi-structured interviews with eight staff in the two schools and one parent, and ethnographic observation, also provide background context.

The data presented here are part of a broader project, which has involved in-depth research in a total of nine schools (three secondary, three primary and three 'segregated special' schools in three LAs), along with qualitative interviews with key actors across the LAs (total 30). Secondary data analysis of the Annual Schools Census (ASC) was also conducted. In this paper, we focus on the experience of young people with socio-emotional differences in two of the three secondary schools, where there were both a high proportion of young people with socio-emotional differences (in contrast to the third secondary school where there were none) and 
Emotions and the habitus: young people with socio-emotional differences (re)producing social, emotional and cultural capital in family and leisure space-times

specific 'units' for young people diagnosed with SEBD. There were similarities of experience of young people across the two schools. Notable here are the themes of negative relationships to formal schooling and social relationships in school, along with the importance of family, leisure activities and friends outwith school, which form the core of this paper. However, the data are open to being analysed in different ways, for instance by comparing experiences in different types of school (special, secondary, primary) and across LAs.

Research was undertaken with approximately twelve young people and semistructured interviews with three or four adults in each school. The methods were designed to be semi-participatory, giving young people a voice over the kinds of data collection methods they used and including their experiences in analysis. (Although in addition to more creative methods, all young people were invited to participate in semi-structured interviews in pairs or individually, according to their preference). It was not a fully participatory study: the young people did not set the research questions, for instance. In the two secondary schools discussed here, the young people unanimously expressed a preference for self-directed photography. The parents or carers of all the young people who participated in the research were invited to participate in the study.

The research with the young people consisted of repeat (two) interviews and selfdirected photography. The young people were given limited directions as to what or how many photographs to take, although there was a maximum of 24 photos, which 
Emotions and the habitus: young people with socio-emotional differences (re)producing social, emotional and cultural capital in family and leisure space-times

was the number of exposures on the camera. They were shown how to use the cameras and requested to take photographs of anything, people or places of importance to them. The young participants took differing numbers of photos, ranging from five or six to 24 . The photos were used to prompt discussions in the second semi-structured interview.

Approximately 30 days of participant observation were undertaken in each school. A diversity of spaces was observed, from classrooms, playgrounds, lunchrooms to 'special units', at a variety of times. The focus of the observations was young people's socio-cultural interactions with other youths and adults. The observations were recorded in note form at the time and then written fully into a research diary as soon as possible after the observation. The observations were overt, and young people had received information about the project and been given the opportunity to decline to being observed prior to the research commencing. It was not considered practicable to request informed consent of all young people who might be, often glancingly, observed.

Full, written consent was gained, however, from both the young people and parents/carers prior to participation in the interviews and self-directed photography. The nature of the research was fully explained to the young people in appropriate language, both in written form, and verbally, with the opportunity for young people to ask questions and/or for further information. It was made clear to the young people that they could withdraw at any stage and had the right to not participate in or 
Emotions and the habitus: young people with socio-emotional differences (re)producing social, emotional and cultural capital in family and leisure space-times

respond to any aspect of the study. Since the requirement for written consent can be a barrier to the participation of some (Cocks, 2006), young participants were given many opportunities to return the written consent form if they continued to express an interest in participating, but claimed to have forgotten or mislaid their it. The names of the schools, the LAs and all individuals involved in the study have been changed to preserve anonymity and confidentiality.

A thematic, line by line analysis of the interviews and research diaries was undertaken, by hand initially, and then using Nvivo to share the analysis. Rather than being discretely 'in vivo' or 'analytic', the codes were a continuum, more or less grounded in the participants' accounts and our pre-existing theoretical and conceptual frameworks (Kelle, 2007). The codes were then grouped into broader themes. The three key themes that are explored in this paper are (a) familial relationships as a source of social and emotional support; (b) relationships and activities in 'leisure' spaces (both formal and informal) and how these provide social, emotional and cultural capital; and (c) the embodiment of socio-cultural relationships as 'habitus'.

The key way that the photographs were analysed was through the discussion they prompted in the second interview (Jorgenson and Sullivan, 2009). Thematic analysis of the photographs was also undertaken by the research team. The analysis of the photographs followed a critical visual analysis, as outlined by Rose (2001), which, in common with our analysis of the interviews and research diaries, did not 
Emotions and the habitus: young people with socio-emotional differences (re)producing social, emotional and cultural capital in family and leisure space-times

seek an objective truth. Instead, a critical visual analysis that takes account of the importance of images as a medium of representation can go beyond the immediately representational in language (Pink, 2007). These meanings are not self-evident or truthful, but socially situated and representational (Thompson, 2008). The "social conditions and affects" of the photos (Rose, 2001: 15) were critically reflected upon, partly by including young people's analysis of their photos along with a critical analysis by the team. The photos and interviews offer different but interrelated lenses upon the verbally expressed experience of the research participants (Pink, 2007), especially since there was a dialectical relationship between the photographs and young people's self-reflexive discussions.

The data from all sources were collated around each individual young person following initial analysis. The experiences of young people were then explored across different spatial settings. Commonalities and differences in experiences of young people were explored according to various spaces, diagnoses, gender, and so on. The data analysis and collection are discussed in further detail elsewhere (Holt et al., 2013; Lea et al., 2011).

\section{Constructing social, cultural and emotional capital outside the school}

\subsection{Friends, formal and informal leisure activities}

These young people, who have (de)valued identities in school, often created social networks and acquired social and cultural capital outside school. Many of the young 
Emotions and the habitus: young people with socio-emotional differences (re)producing social, emotional and cultural capital in family and leisure space-times

people nurture interests, talents and valued identities in non-school spaces beyond the family. A minority are involved in a formal leisure activities. The talents, ability and interests of those involved in these activities facilitate the acquisition of social and cultural capital, and a positive sense of self as skilled and proficient - a different habitus, which can help to counter negative experiences of school (Section 5). Further, positive social relationships were forged in these settings, based upon mutual interests and respect. Ava is a talented dancer, who dances nearly every evening of the week and at weekends. Along with (re)producing and embodying an alternative habitus as a talented and proficient practitioner, Ava forged friendships and acquired social capital through dancing. Friends from dancing featured highly on Ava's photos (Plate One), and she claimed that a key reason she liked dancing was because of the social relationships she forged and maintained through this activity: "Yeah! Well I see my mates and everything all the time when I go there". <<Plate One about here>>

For Ava, and many young people, the experience of acquiring proficiency at a leisure activity was woven intrinsically with the emotionally and socially reciprocal relationships forged in this setting. For Ava, these social networks permeated both school and non-school spaces, as some of Ava's friends from dancing attended her school. Therefore, Ava, despite being presented by teachers as having problematic relationships in school, had a small number of solid friendships forged through her interest in dancing. 
Emotions and the habitus: young people with socio-emotional differences (re)producing social, emotional and cultural capital in family and leisure space-times

Social relationships created in informal leisure spaces can provide a similar resource. For instance, the majority of young people with socio-emotional differences report having informal friendships in their neighbourhood and hanging around on the street (Baylina, Ortiz Guitart and Prats Ferret, 2011; Matthews, 2003, Thompson and Philo, 2004). The majority of young people also describe developing and maintaining social relationships in cyberspace. They use social networking sites, such as Facebook and gaming technology, such as Xbox, to create and maintain friendships.

Sometimes these friendships were made primarily in the school space. However, more often contacts began elsewhere, often in primary school, through family members or other friends, or through social activities (Blazek, 2011). As Maddox emphasises:

M: I love hanging round with my mates. I love going to my dad's, seeing my little brothers and my dad and my step-mum. I love playing sport....

JL: That sounds good. So when you're hanging round with your mates, like what kind of things do you? Like what is hanging around?

M: Oh sometimes I just get up to trouble.

$\mathrm{JL}:$ Ah ah. 
Emotions and the habitus: young people with socio-emotional differences (re)producing social, emotional and cultural capital in family and leisure space-times

M: But we don't do that anymore because it's just like, we're going to lead down, the older lot that used to be like us, we don't want to be like them. So now we just walk around talking. And with my other mates who don't, like hate trouble, like Jayden and that lot, I go round their house and play Call of Duty or we ride on our bikes and stuff.

$\mathrm{JL}:$ OK, so are they all friends through school; that you made through school or have you got friends outside the school as well?

M: No just friends outside of school as well.

JL: Have you, so how did you meet them? Is that through like an old school or ...?

M: Yeah, I met Damian through my old school, he don't go to this school.

Although mostly not created in the current school, these friendships sometimes extend into the permeable school space, providing emotional support there too. For instance James and Keith were friends both inside and outside the school. Their friendship was forged at primary school, and provides important emotional and social support, especially for James who is relatively isolated at school. 
Emotions and the habitus: young people with socio-emotional differences (re)producing social, emotional and cultural capital in family and leisure space-times

These informal social relationships provide 'emotional capital' to young people. The 'value' of the social capital constructed via young people's sociality, and its possibilities for 'conversion' into other (notably cultural) forms of capital are variable, however. Membership of certain social groups is based upon embodying a risktaking habitus (Sharland, 2006), such as smoking, drinking alcohol, taking illicit drugs or simultaneously taking mind-altering drugs and playing gratuitously violent computer games, which resonate with states of mental ill-health. Plate Two shows Simon's smoking equipment and Plate Three, also taken by Simon, shows bottles of alcohol, which he discusses drinking with friends. Simon clearly took photos of these things because they have an important role in his life, and/or represented an aspect of himself he wanted to perform to the researcher. The photos prompted discussion of smoking and drinking.

<<Plate Two about here>>

$<<$ Plate Three about here $>>$

Jimmy discusses his drug-taking practices:

$\mathrm{J}$ : I am a cannabis user.

$\mathrm{JL}:$ OK, yeah. 
Emotions and the habitus: young people with socio-emotional differences (re)producing social, emotional and cultural capital in family and leisure space-times

J: So basically go home ...<.. > Sometimes I do it at home, but that's like if no one's in. $<\ldots>$ Most of the times I go outside with a couple of mates.

JL: Ah ah, so have you got somewhere that you can go that you can like meet up with people that smoke or do you just do it on your own?

J: Usually I go round my mate Peter's house because his mum and dad, well his dad usually goes to the pub and his mum usually works at about half 6,7 ish, so we can just round his with all the windows open and that.

$\mathrm{JL}: \mathrm{OK}$, so is that on weekends, not on evenings?

J: Yeah, weekends.

JL: Yeah, more at the weekends. So do you, what do you chat, do you listen to music, play computer games?

$\mathrm{J}$ : Listen to music and play games really. And there's this one game at the moment, it's called Amnesia, I shit my pants ....

These social relationships provide an alternative habitus as an accomplished drinker, smoker or drug taker. However, such attributes are widely devalued in broader society. Therefore the potential social and cultural capital (re)produced by differing social relations are variable. The variability of social relationships in relation to the social and cultural capital they (re)produce also demonstrates the problematic question of when emotionally supportive relationships provide 'capital' (Reay, 2004). It is, however, difficult to draw distinctions between relationships that provide 'capital' and those that do not, without assuming that the value of emotional and other capital(s) is ultimately connected to being able to maintain or enhance positional advantage within particular fields. This can be problematic, suggesting that the 
Emotions and the habitus: young people with socio-emotional differences (re)producing social, emotional and cultural capital in family and leisure space-times

value of social or emotional exchanges are limited to the extent to which they can be converted into other forms of capital, ultimately economic, and therefore, implicitly, endorsing the idea of the sovereignty of the economic (Bourdieu, 1986). There is a danger that such distinctions (re)produce hierarchies of 'value', with middle-class emotional relations being accorded greater value than those of working class or socially excluded groups iii. Here we avoid attempting to differentiate between different capital values of emotional inter-dependencies, suggesting that all emotionally reciprocal relationships provide capital. We argue that these emotional relationships are valuable and even foundational for individuals (Butler, 2004). However, these relationships occur in different constellations of social, cultural and economic capital. Thus, the emotional capital embedded in nurturing relationships give differential access to other forms of capital, due to the broader socio-spatial contexts in which these relationships are embedded, a point Reay (2004) hints at but does not fully develop. The emotional recognition (Butler, 2004) sought by young people leads to subjection within particular and, in some cases risk-taking, forms of habitus (Section 5).

\subsection{Families}

Families are pivotal in encouraging or discouraging social interaction and involvement in formal or informal leisure activities. Parents are important for a range of reasons from (dis)allowing young people the freedom to forge relationships and socialise 'on the street' or to attend formal and informal leisure activities; through providing transport (either directly or paying for transport); to actively promoting 
Emotions and the habitus: young people with socio-emotional differences (re)producing social, emotional and cultural capital in family and leisure space-times

social relationships with their own friends' children or organisations they are involved in. Siblings can provide more freedom for travel or facilitate involvement in formal or informal leisure activities and/or accompany younger siblings (or those viewed as less competent so that having a disability could over-ride age, gender or birth order in parental views of relative competence) to local leisure spaces, such as parks or the town centre. Not all families have the same economic, social and cultural capital to facilitate 'leisure' activities, with differing levels of economic resources, social relationships and/or dispositions towards either formal activities or allowing the informal sociality of young people on 'the street'. Families' capitals and dispositions are highly influential to young people's social lives.

Young people report enjoying spending time with a range of family members including siblings, parents and step-parents (demonstrating that blended families often had positive relationships, along with bringing some problems such as negotiating two homes), cousins, aunts and uncles, and grandparents. In the quotation in Section 4.1, Maddox identifies spending time with specific family members as one of the things he loves doing. These positive family relationships are powerful settings, within which particular types of habitus are reproduced and embodied. The importance of these emotionally nurturing relationships to these young people underpins the subjection of young people (Butler, 1997), the coconstruction and embodiment of particular habitus (Bourdieu, 1990), and the embodiment of cultural capital.

Some young people have shared interests that they have developed with family 
Emotions and the habitus: young people with socio-emotional differences (re)producing social, emotional and cultural capital in family and leisure space-times

members, ranging from listening to music, clothes shopping (Rawlings, 2006), going to cafes, playing sport to building things together. (However, a minority reported that they hated clothes or food shopping with parents.) In common with some formal leisure activities, these emotionally nurturing relationships based on interests shared with parents and family members provide a source of cultural capital to young people. In some cases, these activities suggest a possible route for a future career, which, importantly, did not depend on a high level of success in formal qualifications. This is crucial for many of these young people who, although largely pro-education, are not able to participate fully and find it difficult to succeed at formal schooling. For instance, Maddox's family love music and his uncle is involved in the music industry. This has facilitated access to a recording studio where he has recorded a rap song. In these family settings, an alternative habitus is reproduced, which can be embodied by the young people and provide a sense of proficiency and talent, in contrast to their largely negative perceptions of their level of success at school.

\section{Emotional Capital, Subjection and the Embodiment of Habitus}

Young people find it difficult to express the emotionality of friendships and familial relationships. This is unsurprising, since such elements of life elude straightforward representation (Bondi, Davidson and Smith, 2007). Nonetheless, these young people feel strongly that mutual trust and a specific emotional reciprocity is an important characteristic of friendships. In the words of Ava: "I just like telling them [my friends] everything, like I can trust them, well I can trust like a few of my mates, like my best mates ... And they always tell me stuff as well". Mark also claims of his 
Emotions and the habitus: young people with socio-emotional differences (re)producing social, emotional and cultural capital in family and leisure space-times

two best friends: "They're my friends and like they're trustworthy". To Mark being trustworthy and being friends are synonymous. Thus, friendships provide emotional support and what we label a convivial habitus, typified by nurturing socio-emotional relations. This convivial habitus, wherein nurturing emotional relationships are forged, provides the setting for the (re)production of social and sometimes cultural capital.

This sense of trust and reciprocity is central to a convivial habitus. For many of the young people, the importance of trust and emotional reciprocity to friendships (and consequently the acquisition of social and often cultural capital), is brought to the fore by contrast with direct experiences of betrayal of trust:

“Yeah, it's just sort of like everything, you don't want like [people] spreading stuff and people spread stuff, you know who it's come from like because you've just told people stuff...But yeah, that's what l'd like to change, no one like telling the secrets, I ..." (Simon).

Indeed, relationships are always, to differing degrees, conflictual and risky (Ní Laoire, 2011). Often, however, social relationships outside the school provide a source of embodied social capital and they help young people to embody a positive habitus, often in opposition to the ways in which their identities are (de)valued in other (notably school) contexts.

Family relationships also provide important emotional support for these young 
Emotions and the habitus: young people with socio-emotional differences (re)producing social, emotional and cultural capital in family and leisure space-times

people, and are largely discussed positively (Valentine, 2008; Valentine and Hughes, 2011a, b). Only one participant cast her relationship with her family as largely negative and conflictual. Thus, families, even those which are often defined as problematic by key actors in schools and LAs (as those of young people with socioemotional differences often are) provide an important emotional resource and social and cultural capital for young people, and an important context for the subjection of young people and for the acquisition of cultural capital.

Although it is difficult to explore how young people embody a more positive habitus, three insights into this are provided here in relation to friends and families. First, most of the young people believe that they embodied the characteristics that they value in friends, suggesting that they have incorporated a positive habitus of themselves as having these attributes. Along with being trustworthy, being funny is another highly valued attribute of friends, and many of the young people consider themselves to be both funny and trustworthy. This contrasts with aspects of their personality that the young people recognised as problematic, particularly within the school space, such as seeming aggressive, getting easily bored and 'playing up'.

Second, despite the negative labels attached to them at school, and sometimes by other agencies, many of the young people with socio-emotional differences say they feel that their parents trust them. This sense of trust is important to the young people and provides them with confidence in their own abilities. As Simon states 
Emotions and the habitus: young people with socio-emotional differences (re)producing social, emotional and cultural capital in family and leisure space-times

"But I think my mum and dad trust me with stuff, like they don't think I'll go off and cause trouble, well I don't, it's just it's quite sort of deep for my parents...".

Third, social relationships with friends in formal and informal leisure activities and familial networks provide settings for the creation of alternative, positive forms of habitus as skilled and proficient at something (including friendships), which constitute a counter-habitus to negative perspectives of themselves as schooled subjects, which they and others also hold. For instance, Ava considers herself to be a skilled dancer. Other young people develop skills and attributes that they embodied via family activities. For instance, Simon spends some of his free time with his dad, who is a carpenter, building things. This experience gives Simon a sense that he is good at making things, but also a more generalised, embodied, ability to learn practical skills easily:

"Yeah, I pick up things easily. We have like a couple of weeks, like months ago, I helped my dad build, because he does like pigeon racing and he's got this big pigeon shed and everything like, we were doing like brick wall underneath ... Yeah, yeah, and then bricklaying, l'd never done it before, but he just showed me how to do it, I looked at him what he was doing, I picked it up so easily and just did it".

These emotionally interdependent friendship and familial relationships provide the context for the reproduction of particular habitus, and for subjection. Butler (2004) suggests that emotionally inter-dependent relations help to explain why individuals 
Emotions and the habitus: young people with socio-emotional differences (re)producing social, emotional and cultural capital in family and leisure space-times

implicate themselves in subjection, accepting normative conditions which circumscribe their potential expressions of identity. Clearly, young people can be subjected in different ways in differing contexts. For instance, Simon sometimes performed an appropriately drinking and smoking subject with his friends, embodying a particular habitus (Section 4.1). However, he also explains how the investment in trust from his parents encourages him to try to improve his behaviour at school. In common with most adults, many of the young people view their socio-emotional differences as a personal deficiency in appropriate behaviour. Simon attempts to forge himself into an appropriate 'learning' subject, with potential implications for his acquisition of, most obviously cultural, but also implicitly social, capital:

S: ... that's why I try and behave at school for mum and dad because they don't like it, because it's sort of hassle for them.

$\mathrm{JL}$ : Of course, of course.

S: And it's embarrassing, if you think about like your kid, you're not speaking with your parents, and them like speaking with their mates that...that like their kids are like $A^{*}$ students and like their kid's like in trouble all the time. So that's the reason I try and behave, for like my parents, because they give me so much, like everything, when I want a new bike, my dad just goes out and buys me a new bike and when I want a new pushbike, my dad will just go out ... And I'm so lucky, but I just thought I throw back in their faces ... 
Emotions and the habitus: young people with socio-emotional differences

(re)producing social, emotional and cultural capital in family and leisure space-times

\section{Conclusion}

In this paper, we have argued for the importance of the emotional, not only as another type of capital (Reay, 2004a), but as underpinning the acquisition of social and cultural capital, given the importance of affective relationships that provide emotional recognition (Butler, 2004) in reproducing social and cultural capital. We have traced how young people with socio-emotional differences, whose identities are generally devalued by both formal and informal aspects of schooling, co-create social and emotional capital via emotionally reciprocal, affective relationships with friends and family in familial and informal and formal leisure spaces. The young people who participated in the research demonstrate that taking part in leisure activities (both formal and informal) with others contributes to the development of their own sense of self and positive social relationships. Even when these friendships are located strictly outside school, the social and emotional capital gained (such as the self-identification as someone who is competent at making and maintaining social relationships, or the value gained from emotional recognition) generally 'travelled' into the school context. This is particularly interesting given that part of the designation of these young people as socially and/or emotionally different is because of perceptions of their lack of success at social relationships within school, with teachers and other adults, and their peers.

What the data underline is that that social relationships are not straightforwardly positive or negative, but rather need to be analysed in the contexts in which they are made, maintained and negotiated. While they may provide different levels of access 
Emotions and the habitus: young people with socio-emotional differences (re)producing social, emotional and cultural capital in family and leisure space-times

to social and cultural capital, the data show that they are always valued by the young people in (re)producing some emotional reciprocity, which provides young people a counter-habitus with which to contest (dis)abling experiences in school. The experiences of the young people who took part in the research problematises normative societal judgements made about the value of friendships and social relationships within such institutions as schools, which constitute an important aspect of the diagnosis of these young people as having Social, Emotional and Behavioural Difficulties. Nonetheless, the young people's experiences underline the fact that their social relationships are never only emotionally nurturing, but are also variously conflictual and problematic.

These emotionally charged relationships provide an important context for subjection (Butler, 1997, 2004). Individuals' yearning for emotional recognition helps to explain how and why individuals accept and embody particular conditions of capital and/as habitus. (Although these conditions are not static, and habitus is open to transformation). Rather than conflicting, then, we have found Bourdieu's (1986, 1990) concepts of capitals and habitus and Butler's (1990, 1993, 1997, 2004) theories of subjection and emotional recognition to be complementary (Butler, 1999). Butler (2004) usefully considers the mechanisms by which individuals become subjected in power and situates the need for emotional recognition at the heart of these mechanisms. Butler's theories have been extended here to explore how and why individuals embody particular habitus. Via his attention to habitus and capitals, Bourdieu reminds us of the importance of individuals' positioning in relation to a 
Emotions and the habitus: young people with socio-emotional differences (re)producing social, emotional and cultural capital in family and leisure space-times

variety of capitals, which, he claims, are ultimately bound to the capitalist politicaleconomy (Bourdieu, 1986), usefully grounding Butler's accounts in the importance of socio-economic, along with other, differentiations.

From the foregoing discussion of our empirical findings, we suggest that these emotionally inter-dependent relationships and the need for emotional recognition underpin the acquisition of social and cultural capital among the young people discussed in this paper, and possibly more widely. Thus, emotional capital, as coined by Nowotny (1981) and further conceptualised by Reay (2004), might have a far wider importance than envisaged by these authors and be of keen interest to geographers interested in affective/emotional aspects of life. Rather than being another form of capital, emotional, affective, relationships are pivotal, even foundational, to reproducing social and cultural capital amongst these young people. This might have a broader resonance to the interconnections between emotions, the reproduction of habitus, and subjection.

\section{References}

Anderson, Ben, and John Wylie. 2009. On geography and materiality. Environment and Planning A 41 (2): 318.

Baylina, Mireia, Anna Ortiz Guitart, and Maria Prats Ferret. 2011. Children living in the city: Gendered experiences and desires in Spain and Mexico. In Geographies of children, youth and families: An international perspective. ed. Louise Holt, 153-166. London: Routledge.

Blazek, M. 2011. Place, children's friendships, and the formation of gender identities in a slovak urban neighbourhood. Children's Geographies 9 (3-4): 285-302. 
Emotions and the habitus: young people with socio-emotional differences

(re)producing social, emotional and cultural capital in family and leisure space-times

Bondi, Liz, Joyce Davidson, and Mick Smith. 2007. Introduction: Geography's 'emotional turn'. In Emotional geographies.eds. Joyce Davidson, Mick Smith and Liz Bondi, 1-18. Aldershot: Ashgate Publishing.

Bondi, Liz. 2005. Working the spaces of neoliberal subjectivity: Psychotherapeutic technologies, professionalisation and counselling. Antipode 37 (3): 497-514.

Bourdieu, Pierre, and Jean Claude Passeron. 1979. The inheritors: French students and their relation to culture. Chicago, IL: University of Chicago Press.

Bourdieu, Pierre, and John Thompson. 1991. Language and symbolic power. Cambridge MA: Harvard Univ Press.

Bourdieu, Pierre. 1984. Distinction: A social critique of the judgement of taste. Cambridge MA: Harvard Univ Press.

Bourdieu, Pierre. 1986. The forms of capital. In Handbook of theory and research in the sociology of education, ed. John Richardson, 280-291Wiley Online Library.

Bourdieu, Pierre. 1990. The logic of practice. Stanford CA: Stanford Univ Pr.

Bridge, Gary. 2006. It's not just a question of taste: Gentrification, the neighbourhood, and cultural capital. Environment and Planning A 38 (10): 1965-78.

Butler, Judith. 1990. Gender trouble: Feminism and the subversion of identity. New York: Theatre Arts Books.

Butler, Judith. 1993. Bodies that matter: On the discursive limits of "sex". New York: Routledge.

Butler, Judith. 1997. The psychic life of power: Theories in subjection. Stanford, CA: Stanford University Press.

Butler, Judith. 1999. Performativity's social magic. In Bourdieu: A critical reader. ed. R. Shusterman, 113-128. Oxford: Blackwell.

Butler, Judith. 2004. Undoing gender. New York: Routledge.

Cocks, A. J. 2006. The ethical maze. Childhood 13 (2): 247-66.

Colls, Rachel. 2011. Feminism, bodily difference and non- representational geographies. Transactions of the Institute of British Geographers Early view online.

Crang, Mike. 2001. Filed work: Making sense of group interviews. In Qualitative methodologies for geographers: issues and debates. eds. Melanie Limb, Claire Dwyer, 215-233. Oxford: Oxford University Press. 
Emotions and the habitus: young people with socio-emotional differences

(re)producing social, emotional and cultural capital in family and leisure space-times

Cresswell, Tim. 2004. Place: A short introduction. Vol. 3Wiley-Blackwell.

Davidson, Joyce, and Hester Parr. 2010. Enabling cultures of dis/order online. In Towards enabling geographies: 'disabled' bodies and minds in society and space.eds. Vera Chouinard, Ed Hall and Robert Wilton, 63-84. Farnham, UK: Ashgate.

Davidson, Joyce. 2010. 'It cuts both ways': A relational approach to access and accommodation for autism. Social Science \& Medicine 70 (2): 305-12.

Dowling, Robyn. 2009. Geographies of identity: Landscapes of class. Progress in Human Geography 33 (6): 833.

Dyson, Jane. 2010. Friendship in practice: Girls' work in the Indian Himalayas. American Ethnologist 37 (3): 482-98.

Gallagher, Michael 2011. Sound, space and power in a primary school. Social \& Cultural Geography 12 (01): 47-61.

Grenfell, Michael. 2004. Pierre Bourdieu, Agent Provocateur. London: Continuum.

Harker, Christopher. 2010. On (not) forgetting families: Family spaces and spacings in Birzeit, Palestine. Environment and Planning A. 42 (11): 2624-39.

Hollingworth, Sumi, Katya Williams, Fiona Jamieson, and Phoebe Beedell. 2011. Social and educational inequalities in English state schools. In Geographies of children, youth and families: An international Perspective. ed. Louise Holt, 250264. London: Routledge.

Holt, Louise, Sophie Bowlby, and Jennifer Lea. 2012. "Everyone knows me ....I sort of like move about": Habitus, young people's embodied social capital and disability - implications for the intergenerational (re)production of (in)equality. Working Paper Available from Authors.

Holt, Louise, Sophie Bowlby, and Jennifer Lea. 2013. Children's embodied social capital and (dis)ability: Connecting micro- and macro- scales of exclusion: Final project report. London: Economic and Social Research Council.

Holt, Louise. 2007. Children's sociospatial (re) production of disability within primary school playgrounds. Environment and Planning D: Society and Space 25 (5): 783-802.

Holt, Louise. 2008. Embodied social capital and geographic perspectives:

Performing the habitus. Progress in Human Geography 32 (2): 227.

Holt, Louise. 2010. Young people's embodied social capital and performing disability. Children's Geographies 8 (1): 25-37. 
Emotions and the habitus: young people with socio-emotional differences

(re)producing social, emotional and cultural capital in family and leisure space-times

Holt, Louise. 2010. Young people with socio-emotional differences: Theorising disability and de-stabilizing socio-emotional norms. In Towards enabling geographies: Disabled bodies and minds in society and space., eds. Vera Chouinard, Ed Hall and Robert Wilton, 145-164. Farnham, UK: Ashgate.

Jackson, Peter. 2000. Rematerializing social and cultural geography. Social \& Cultural Geography 1 (1): 9-14.

Jeffrey, Craig. 2010. Geographies of children and youth I: Eroding maps of life. Progress in Human Geography 34 (4): 496.

Jorgenson, Jane, and Tracy Sullivan. 2009. Accessing children's perspectives through participatory photo interviews. Forum Qualitative Sozialforschung/Forum: Qualitative Social Research 11, (1), http://www.qualitativeresearch.net/index.php/fqs/article/viewArticle/447.

Kelle, Udo. 2007. The development of categories: Different approaches in grounded theory. In Sage handbook of grounded theory. eds. Antony Bryant, Kathy Charmaz, 191-213. London: Sage.

Kenway, J., and D. Youdell. 2011. The emotional geographies of education: Beginning a conversation. Emotion, Space and Society 4 (131): 136.

Lea, Jennifer, Louise Holt, and Sophie Bowlby. 2012. Participatory techniques and the reproduction of classed expectations of social expression. Working Paper Available from Authors.

Lewis, R. 2011. 5 shutting the bathroom door. In Geographies of children, youth and families: An international Perspective. ed. Louise Holt, 67-80. London: Routledge.

Lizardo, Omar. 2004. The cognitive origins of Bourdieu's habitus. Journal for the Theory of Social Behaviour 34 (4): 375-401.

Longhurst, Robyn. 1997. (Dis)embodied geographies. Progress in Human Geography 21 (4): 486.

Manning, Rachel, Robert Jago, and Julia Fionda. 2011. Socio-spatial experiences of young people under anti-social behaviour legislation in England and wales. In , ed. Louise Holt, 221-232. London: Routledge.

Matthews, Hugh. 2003. 7 the street as a liminal space. In Children in the city: Home, neighborhood and community.eds. Pia Christensen, Margaret O'Brien, 101-117. London: Routledge.

McDowell, Linda. 2003. Redundant masculinities?: Employment change and white working class youth. Vol. 2. Oxford: Wiley-Blackwell. 
Emotions and the habitus: young people with socio-emotional differences

(re)producing social, emotional and cultural capital in family and leisure space-times

McDowell, Linda. 2006. Reconfigurations of gender and class relations: Class differences, class condescension and the changing place of class relations. Antipode 38 (4): 825-50.

McNay, Lois. 2004. Agency and experience: Gender as a lived relation. The Sociological Review 52 : 173-90.

Ní Laoire, Caitríona. 2011. 'Girls just like to be friends with people': Gendered experiences of migration among children and youth in returning Irish migrant families. Children's Geographies 9 (3-4): 303-18.

Nowotny, Helga. 1981. Women in public life in Austria. In Access to power: Crossnational studies of women and elites., eds. Cynthia Fuchs Epstein, Rose Laub Coser.

Philo, Chris. 2000. More words, more worlds: Reflections on the 'cultural turn' and human geography. In Cultural turns/geographical turns: Perspectives on cultural geography., eds. lan Cook, David Crouch, Simon Naylor and James Ryan, 2653Prentice Hall: Saddle River, NJ.

Pink, Sarah. 2007. Doing visual ethnography: Images, media and representation in research. Sage Publications Ltd.

Rawlins, Emma. 2006. Mother knows best? Intergenerational notions of fashion and identity. Children's Geographies 4 (3): 359-77.

Reay, Diane. 2004. 'It's all becoming a habitus': Beyond the habitual use of habitus in educational research. British Journal of Sociology of Education 25 (4): 431-44.

Reay, Diane. 2004. Gendering Bourdieu's concepts of capitals? emotional capital, women and social class. The Sociological Review 52 : 57-74.

Reay, Diane. 2007. 'Unruly places' : Inner-city comprehensives, middle-class imaginaries and working-class children. Urban Studies 44 (7) (June 01): 1191201.

Rose, Mitch 2002. The seductions of resistance: Power, politics, and a performative style of systems. Environment and Planning D 20 (4): 383-400.

Sakellariadis, Artemi, 2012. A wider sense of normal? seeking to understand pierre rivière through the lens of autism. Emotion, Space and Society. Online early view http://dx.doi.org/10.1016/j.emospa.2012.03.003,

Sharland, Elaine. 2006. Young people, risk taking and risk making: Some thoughts for social work. British Journal of Social Work 36 (2): 247-65. 
Emotions and the habitus: young people with socio-emotional differences

(re)producing social, emotional and cultural capital in family and leisure space-times

Skeggs, Beverley. 2009. The moral economy of person production: The class relations of self- performance on 'reality' television. The Sociological Review 57 (4): 626-44.

Smith, Darren Paul, and Deborah A. Phillips. 2001. Socio-cultural representations of greentrified Pennine rurality. Journal of Rural Studies 17 (4): 457-69.

Thomas, Mary E. 2010. Introduction: Psychoanalytic methodologies in geography. The Professional Geographer 62 (4): 478-82.

Thomson, Joanne L., and Chris Philo. 2004. Playful spaces? A social geography of children's play in Livingston, Scotland. Children's Geographies 2 (1): 111-30.

Thomson, Pat. 2008. Children and young people: voices in visual research. In Doing Visual Research with Children and Young People. ed. Pat Thompson, 1-20. London: Routledge.

Valentine, Gill, and Kathryn Hughes. 2011. Geographies of 'family' life. In Geographies of children, youth and families: An international perspective. ed. Louise Holt, 121-135Taylor \& Francis.

Valentine, Gill, and Kathryn Hughes. 2011. Shared space, distant lives? understanding family and intimacy at home through the lens of internet gambling. Transactions of the Institute of British Geographers.

Valentine, Gill, and Sarah Holloway. 2001. On-line dangers?: Geographies of parents' fears for children's safety in cyberspace. The Professional Geographer 53 (1): 71-83.

Valentine, Gill, and Sarah Holloway. 2002. Cyberkids? Exploring Children's identities and social networks in On- line and Off- line worlds. Annals of the Association of American Geographers 92 (2): 302-19.

Valentine, Gill. 2008. The ties that bind: Towards geographies of intimacy. Geography Compass 2 (6): 2097-110.

Waters, Johanna. 2006. Geographies of cultural capital: Education, international migration and family strategies between Hong Kong and Canada. Transactions of the Institute of British Geographers 31 (2): 179-92.

Werner, Jayne. S. 2006. Between memory and desire: Gender and the remembrance of war in doi moi vietnam. Gender, Place and Culture 13 (3): 30315.

Wills, Jane. 2008. Mapping class and its political possibilities. Antipode 40 (1): 25-30. 
Emotions and the habitus: young people with socio-emotional differences
(re)producing social, emotional and cultural capital in family and leisure space-times

\author{
Youdell, Deborah, and Felicity Armstrong. 2011. A politics beyond subjects: The \\ affective choreographies and smooth spaces of schooling. Emotion, Space and \\ Society 4 : 144-50.
}

\footnotetext{
'The term socio-emotional differences was coined by Holt (2010). Young people with socio-emotional and differences are those categorised as having Social, Emotional and Behavioural Difficulties (SEBD) via the Special Educational Needs (SEN) institution in the UK. Such young people are diagnosed as having SEBD because their behaviour and/or emotional state is viewed as presenting a barrier to their learning. The term differences rather than difficulties is a strategic attempt to express that the differences are located at least as much in socio-spatially specific and constructed normative expectations of behaviour and emotional competence as within the mind-body-emotions of the young people. Thus these young people are dis-abled specifically due to their inability to embody and reproduce socio-spatially specific norms of emotional and behavioural performance. The diagnosis SEBD is specifically located within the SEN institution. Some young people have more specific diagnoses such as Attention Deficit and Hyperactivity Disorder (ADHD) or Attention Deficit Disorder (ADD). Some young people with socio-emotional differences are subject to further diagnosis and are placed on the Autistic Spectrum. In some cases young people have multiple diagnoses including both SEBD and ASD and/or SEBD and specific or non-specific learning difficulties.

ii Local Authorities (LAs) are the local administrative organisation of the education system in England.

iii This danger is implicit rather than explicit in Reay (2004), which does accord emotional capital to groups other than the middle-classes and suggests that the tendency to put excessive pressure on young people to achieve educationally in many middle-class households reduces emotional capital. Nonetheless ascribing capital to some emotional relationships and not others requires, in our view, a problematic value judgement.
} 